DOI: 10.20472/IAC.2018.039.012

\author{
ASLI E. MERT
}

Koç University, Turkey

\title{
HOW ARE DIFFERENT MEANS OF HAPPINESS RELATED? LIFE, JOB AND INCOME SATISFACTION IN TURKEY
}

\begin{abstract}
:
This study investigates life (happiness), job and income satisfaction of women and men in paid work according to different demographic and value-based (in terms of the values associated with paid work and income) components, and to the extent they are correlated (findings are derived using the Life Satisfaction Survey (2016) provided by Turkish Statistical Institute). Preliminary descriptive statistics refer to relatively lower income satisfaction levels of women and men in Turkey (46.0 per cent of women and 48.6 per cent of men report that they are "satisfied" or "very satisfied" with their income), moderate levels of overall happiness levels (59.1 per cent of women and 59.6 per cent of men report that they are "happy" or "very happy" with their lives) and relatively higher levels of job satisfaction (81.0 per cent of women and 80.9 per cent of men report that they are "satisfied" or "very satisfied" with their jobs).
\end{abstract}

Spearman's rank correlation coefficients demonstrate that happiness (life satisfaction) levels of women and men in paid work are positively correlated with their job and income satisfaction levels, and there is also a positive correlation between their job satisfaction and income satisfaction levels, all of which are on a weak to moderate level yet statistically significant. For men, the correlation between happiness and job satisfaction has the lowest (yet positive) value, whereas for women the lowest (though positive) value is observed for the relationship between happiness and income satisfaction. For both women and men, the correlation between job satisfaction and income satisfaction has the highest value, which is slightly stronger for women. The findings of this study support the spillover hypothesis, which claims that life and job satisfaction are positively correlated (income satisfaction also being involved in this context) as these components affect each other (Strauser, 2014).

Strauser, D. R. (2014). Career development, employment, and disability in rehabilitation: From theory to practice. Springer Publishing Company.

Turkish Statistical Institute. (2016). Life satisfaction survey.

\section{Keywords:}

Sociology of Happiness, Sociology of Economics, job satisfaction, life satisfaction, gender and happiness, income satisfaction, happiness, well-being, spillover hypothesis

JEL Classification: A14, J28, J01 